\title{
Discussion and Research on the Professional English Reform of Automotive Major in Vocational Colleges Based on Ability
}

\author{
Yan $\mathrm{Hu}$ \\ Sichuan Vocational and Technical College, Suining, Sichuan 629000, China
}

\begin{abstract}
At present, the country popularizes higher education, and higher English education has accounted for $52 \%$ of higher education. Higher vocational students feel the importance of higher education thus education reform is very important. Higher vocational graduates are showing an increasing trend every year, and the overall employment environment is good. With the integration of the world economy, the employment market provides more opportunities for graduates, and various employment systems or security systems are becoming perfect. These excellent conditions will undoubtedly bring more opportunities for the employment of students in higher vocational colleges. As a general communicative language, English is becoming more important in terms of employment and career advancement, which has even become a measure of the quality of a person to some extent. English teaching reform is a comprehensive analysis of the activities of professional roles, making students can have the skills necessary to engage in a specific occupation.
\end{abstract}

Keywords: Employment planning, Learning ability, English teaching, Teaching reform, Selfevaluation.

\section{Introduction}

German educator Roth believed that professional competence includes self-ability, social ability, method ability and professional ability. After the Second World War, education and training based on professional ability gradually formed in the United States, and American experts and scholars paid more attention to professional ability. American educator J.A. Bowden believed that ability is a combination of skills, knowledge, and attitudes that people demonstrate when performing typical tasks. With the deepening development of China's socialist market economy and the acceleration of global economic integration, foreign-funded enterprises and joint ventures are increasing. China has gradually become the world's manufacturing center, and enterprises need to employ a large number of talents in English majors.

Higher vocational education must not only aim at employment, but also lay a solid foundation for the subsequent development and improvement of students. The development of society is a continuous and dynamic process, and graduates of higher vocational schools must meet the comprehensive requirements for adapting to social development. Some scholars and experts in China have also made different divisions of professional competence. Deng Zemin proposed that professional ability is divided into two aspects: basic professional ability and comprehensive professional ability. Jiang Naiping believed that professional ability can include professional ability, method ability, social ability and practical ability. Their understanding of the structure of professional ability is also the most practical guiding significance for cultivating professional ability. Professional ability has gradually become the goal of cultivating talents in China. In Schultz's theory, capital exists in two forms: physical capital and human capital. Physical capital is a certain number of things, and human capital is embodied in the workers themselves. Human capital is the worker's knowledge, skills, and ability to perform. Because each worker has different qualities and intelligences, after receiving education and training, the working ability, knowledge reserve, and skill level are not the same. Education is composed of different variables, therefore, changing one will inevitably affect the rest of the factors, and the impact will produce different results. It is developed as the economy develops in an unbalanced state. Everyone expects the greatest return on investment in human capital, hence choosing to invest in education must be based on market demand. 


\section{The Proposed Methodology}

\subsection{Analysis of the Current Situation of English Teaching.}

The source of students in higher vocational colleges is much more complicated than that of undergraduate students. Because the English teaching objectives of different schools are very different, the students' English foundation is not balanced, and the differences in their learning motivations bring difficulties to English teaching in higher vocational colleges.

The traditional teaching methods have some drawbacks, which greatly hinder the development of higher vocational education and has become an important reason for the lag of higher vocational English teaching.

Emotion is a filter through which language input must pass, and emotional factors affect the acquisition of a second language. The emotional factors affecting language acquisition in Krashen's theory are: (1) Learning motivation directly affects learning outcomes. If the purpose is clear, the learning motivation will be great, otherwise, it will produce laziness, resistance and other emotions. (2) Learners who are outgoing, confident, and good at communication and who dare to perform can acquire language skills more quickly. (3) Negative emotions can affect the input of language information. When the learner is in a pleasant, relaxed state, he will get more input. The more you type, the more you know, the faster your ability will improve.

First, the source difference is obvious. The students of higher vocational colleges are composed of three parts: high school, technical school and junior high school graduates. The English foundations of students from different teaching environments are very different, which makes synchronous teaching difficult to implement.

Second, the infrastructure is backward. In higher vocational colleges located in prefecture-level regions, the teaching media basically adopts traditional forms and rarely uses multimedia modern teaching methods. Considering the in-depth influence of the college entrance examination on teaching, students have no training in English learning in the middle and high school. The students' ability to listen and speak English is slow, which affects the cultivation and improvement of the comprehensive application of language.

Third, the teachers are weak. English teachers have fewer resources and their knowledge reserves are backward, making it difficult to be qualified for English teaching in emerging majors. Many English teachers have insufficient understanding of the characteristics and special characteristics of English teaching in higher vocational schools, who still stay at the teaching level of vocabulary and grammar.

Fourth, the content is less practical. At present, most of the higher vocational colleges use the unified textbooks in public English, which is not related to the majors they have studied. This leads to the loss of interest and patience of students, and the increase of school-weariness.

\subsection{Ability-oriented Teaching Model.}

Competence is one of the concerns of psychology, and different psychological theories have different definitions of abilities. Vocational education based on the behavioral professional ability concept only emphasizes one-sidedly whether students can complete clear, operative, and evaluable skill behaviors, while ignoring other testable but invisible abilities associated with professional activities.

Cognitiveism believes that understanding and mastering the subject-related knowledge related to the profession is equivalent to obtaining the corresponding professional ability. This view completely ignores the practical requirements of professional ability, and knowledge is not simply equivalent to ability. Higher vocational education has its own particularity. According to the actual needs of skilled talents at the present stage, it has proposed a new concept of vocational ability training for higher vocational students. The new concept of professional ability not only focuses on technology, but also on the role of comprehensive professional quality of workers in professional activities. New skillbased talents not only master several professional skills, but also have the ability to collect, organize, and summarize writing. 
Professional quality is a broad and complex concept, which is a comprehensive manifestation of practitioners' ability to recognize and adapt to social occupations. It is mainly reflected in the professional attitude, practical ability, professional interest and professional cognition status of the practitioners, and is the comprehensive quality of the practitioners in the professional process. Factors affecting professional qualities include: the educational level of the practitioner, values, moral quality, practical experience, work experience, living environment and other characteristics. Professional quality is the personal capital that practitioners must improve and improve, and is the highest standard for talent selection. Vocational quality education is accompanied by the process of the entire career development of practitioners. The goal of basic quality education is to enable educators to master the universal knowledge, concepts, theories and methods to promote the comprehensive and harmonious development of the mind and body of the educated.

\subsection{The Promotion of Higher Vocational English Courses to the Cultivation of Professional Quality.}

Higher vocational English courses are compulsory public foundation courses for higher vocational students. Its significance is reflected in the improvement of students' ability to use English to handle foreign-related work, to successfully complete work tasks, and to achieve a step-by-step development of the cause. On the other hand, it helps to cultivate the professional qualities of students.

First of all, the teaching content of vocational English courses is rich, and promotes the improvement of students' professional quality from different angles. English listening materials often involve different people in different scenes and different industries. Students learn about language exchange and communication skills in different industries and occupations. Through reading materials, students broaden their horizons and understand the history, customs, and technology of different cultures, enriching the spiritual world. Through oral communication in the classroom, students exercise their psychological qualities and cultivate interpersonal skills, collaboration skills, and organizational skills.

English learning has a long-term effect and lays the foundation for students' lifelong career development. Mastered English language skills to understand the most cutting-edge scientific research results and information more broadly and quickly, and promote professional skills. Moreover, through the understanding of the multicultural society in the West and around the world, the development of an open and inclusive personality increases the opportunities for communication and cooperation.

\subsection{Students' Cognition of Occupation.}

Occupational cognition refers to people's understanding and understanding of various information related to occupations, which profoundly affects the establishment of professional values, the establishment of professional ideals and the formation of professional ethics. Occupational cognition is divided into social occupational status cognition and self-career quality cognition Cognition of social occupational status refers to people's understanding and understanding of the status, characteristics, requirements, development trends of social occupational distribution. Selfprofessional quality cognition refers to people's understanding and understanding of their hobbies, advantages, career potential and occupational characteristics.

The survey found that the proportion of teachers holding "double-type" teacher certificates in higher vocational colleges is relatively small. Most English teachers are undergraduate and postgraduate students who have received systematic English knowledge system education. These teachers have a complete knowledge base of English theory, but few teachers have work experience. This has led to the teacher's focus on the systematic teaching of theoretical knowledge in daily teaching, and it is impossible to explain and demonstrate effective practical skills for students in an in-depth and flexible manner.

The teacher's knowledge reserve and professional matching are low, and the knowledge structure needs to be adjusted. With the country's emphasis on and investment in vocational education, the enrollment scale of higher vocational colleges continues to expand, and new professions are 
constantly appearing. This is the rapid increase in the demand for higher vocational teachers and the comprehensive quality requirements of skilled professionals for various professional positions. Only a team of young teachers with solid language skills and strong learning ability can complete the teaching tasks of language teaching and professional integration. The survey found that most of the teachers in public English graduated from English majors, but the language knowledge was abundant but they did not know much about the students. Teachers' practical ability and social activity ability are generally low, and English and major can't be closely combined, which makes students hard to have a strong interest in the English they are learning. It is difficult for teachers to teach.

\subsection{Establishing Vocational Ability-Oriented English Teaching Goals.}

The requirements of English teaching objectives and teaching content in higher vocational colleges reflect the needs of basic knowledge of language, applied skills and humanities. Therefore, we must strengthen the teaching of basic knowledge so that students can use English to communicate fluently. Any learner's learning of the language is not just the language itself. We all know that there is a unique culture behind any language, so it is especially important to understand the cultural connotation behind the language. Therefore, the goal of training in higher vocational colleges should improve the humanistic quality of students. Teachers should explore the cultural connotation of English textbooks and infiltrate the cultural connotations in the teaching process.

The "authenticity" of foreign language learning materials such as texts, images, sound recordings and other materials of the CBI teaching concept is reflected in the language material in which the target language is the mother tongue. That is, all language materials in English teaching activities must use speech materials using English-speaking countries such as English, American and Australian. Teaching activities complete the subject learning tasks through the target language. Using the acquired subject knowledge and understanding of the context, students can acquire new knowledge information, and the difficulty and quantity of new subject knowledge must be controlled within the acceptance ability of students. The motivation and interest in learning comes from the real need for what it is about to understand and the thrill of overcoming cognitive challenges. The organizational form of the teaching activities and the selected course content must conform to the students' language level, cognitive ability and emotional needs.

\section{Conclusion}

The cultivation of professional quality of vocational students is a slow and subtle process. The results will not be immediately highlighted, but it will play a vital role in the entry and subsequent development of students and will benefit students for life. The role of vocational English teaching in the cultivation of high-skilled personnel in the cultivation of students' professional ability and the improvement of professional quality cannot be ignored. The planners and implementers of teaching should clearly recognize the importance of English teaching in vocational colleges. The development of higher vocational education is inseparable from the reform of vocational education. The fundamental problem of education reform is the reform of teaching methods and the reform of curriculum models. The core of talent training in higher vocational education is the cultivation of abilities. Strengthening the construction of the teaching staff, optimizing and improving the teaching environment, and implementing the multi-English proficiency assessment mechanism can fully realize the characteristics of vocational English teaching.

\section{References}

[1]. Harris, R. and Graham, S., 2018. Engaging with curriculum reform: insights from English history teachers' willingness to support curriculum change. Journal of Curriculum Studies, pp.1-19.

[2]. Calhoon-Dillahunt, C., Jensen, D.L., Johnson, S.Z., Tinberg, H. and Toth, C., 2017. TYCA Guidelines for Preparing Teachers of English in the Two-Year College. Teaching English in the Two-Year College, 45(1), p.8. 
[3]. Huang, W., Wang, P., Lv, L., Wang, L. and Wang, H.H., 2018. An inventive high-performance computing electronic information system for professional postgraduate training. International Journal of Computers and Applications, pp.1-7.

[4]. Bryk, A., 2018. Charting Chicago school reform: Democratic localism as a lever for change. Routledge. 